2015

\title{
Preparing Students for Careers in Multichannel Retailing Using an Authentic Experiential Learning Project
}

Sarah Song Southworth

George Fox University, ssouthworth@georgefox.edu

Follow this and additional works at: https://digitalcommons.georgefox.edu/gfsb

Part of the Business Commons

\section{Recommended Citation}

Southworth, Sarah Song, "Preparing Students for Careers in Multichannel Retailing Using an Authentic Experiential Learning Project" (2015). Faculty Publications - School of Business. 110.

https:// digitalcommons.georgefox.edu/gfsb/110 


\title{
Preparing students for careers in multichannel retailing using an authentic experiential learning project
}

\author{
Sarah Song Southworth* \\ Department of Textiles and Apparel Management, University of Missouri, Columbia, MO, USA
}

(Received 9 April 2015; accepted 12 August 2015)

\begin{abstract}
Multichannel retailing education has penetrated into fashion marketing programmes with the emergence of ecommerce. Although class textbooks and lectures help set the curriculum in motion, there is a lack of educational literature on the experiential learning practices in multichannel retailing classes. This paper introduces an experiential learning group project that complements multichannel textbooks and lectures to better prepare students for careers in the multichannel retailing world. The project specifically assigned students the task of building an online presence for actual brick and mortar stores near the university. The four learning modes of experiential learning were used as the framework to record the transformations which occurred from the students' experiences with the project. The learning outcomes demonstrated the students' development of knowledge and skills relevant to careers in today's multichannel retailing environment. Future research opportunities and limitations are also discussed.
\end{abstract}

Keywords: multichannel; education; authentic learning; experiential learning; project; online presence; career

\section{Introduction}

The dynamics of retailing have drastically changed in the last decade with the rise of ecommerce (Morgan Stanley, 2013). The integration of multiple retail channels (i.e. brick and mortar, online, catalogue, mobile), which is called multichannel retailing, has become the standard model of business today (Poloian, 2009). As an increasing number of retail businesses are adapting to this platform, job demands requiring the knowledge and skills in the practice of multichannel retailing are also rising (Heywood, 2013). For example, job descriptions in merchandising expect merchandisers to work with products online and offline interchangeably. Brand managers and PR (public relations) specialists need to be proficient in social media and blogging. Management positions require handling online orders in the brick and mortar stores (Monster.com, 2014). In response to these transformations, fashion business programmes in higher education have been shifting their curriculum to address how online presence influences the multichannel dynamics of retailing. The fostering of this new educational approach has manifested through the use of different retailing textbooks, such as Multichannel retailing (Poloian, 2009) and Fashion retailing: A multichannel approach (Diamond, Diamond, \& Litt, 2015).

Although current textbooks help set this new multichannel curriculum in motion, the development of experiential learning methodologies to complement the course materials is warranted. Because of the practical nature of the fashion discipline, experiential learning is essential to translate the theory-based knowledge in textbooks into practical applications in the industry. Furthermore, given the rapid transformations in the dynamics of multichannel retailing today, it is difficult to update textbooks to match its pace. For these reasons, the purpose of this paper is to introduce an experiential learning project that complements the current multichannel textbooks to prepare students for the multichannel retailing world. The project fosters relevant knowledge and skills that can be adopted by retailing classes involving the discussion of multichannel retailing to better prepare students for future careers in the continuously evolving multichannel retailing world.

\section{Review of literature}

\subsection{Multichannel retailing}

Ecommerce has initiated one of the most dramatic changes in how the customers interact with the retailers. With online retailing, customers can now use multiple channels, such as the Internet, catalogues, brick and mortar, mobile phones, and kiosks, to shop from the same retailer (Carlson \& O'Cass, 2011; Neslin et al., 2006; Poloian, 2009; Teltzrow, Meyer, \& Lenz, 2007; Verhoef, Kannan, \& Inman, 2015). Multichannel retailing gives customers an

*Email: songss@missouri.edu 
opportunity to save their money, time, and effort, as well as help them to shop for a wider assortment of product offerings (Hsiao, Yen, \& Li, 2012). Moreover, customers' satisfaction through these multichannel experiences not only helps increase the retailer's sales (Lewis, Whysall, \& Foster, 2014), but eventually impacts customer loyalty as well (Hsieh et al., 2012). In a retailing world where $86 \%$ of the customers globally are making purchase using at least two channels, having multiple channels to interact with the customers is imperative for retailers' survival (Agnihotri, 2015; PWC, 2011). Thus, most retailers have incorporated ecommerce into their traditional channels (ie. brick and mortar) due to these external pressures (Nikolaeva, 2006). However, there are major challenges that retailers face as a result of this new dynamic. One common challenge is effectively coordinating the different retail channels as one business entity (Lewis et al., 2014; Neslin et al., 2006).

In response, retailers are increasingly recruiting new talents who can adequately understand and manage the multichannel retail environment (Heywood, 2013). Retailers are specifically looking for potential candidates who have an understanding of the targeted consumers' needs and wants from ecommerce and how it interacts with the different retails channels (Heywood, 2013; Monster, 2014). In order to build the students' knowledge and skills relevant to careers in multichannel retailing, this project specifically aims to educate the students about ecommerce and the cohesiveness of the retail channels in the context of having a specific store and target market.

\subsection{Authentic experiential learning}

This project uses an authentic experiential learning approach. Experiential learning theory (ELT) has been widely used in both education and research over the last three decades (Kolb, 1984; Kolb, Rubin, \& McIntyre, 1971). It is the process 'whereby knowledge is created through the transformation of experience' (Kolb, 1984, p. 38). The theory includes a holistic process of adaptation of the total person from experiencing, reflecting, thinking, and acting (Kolb \& Kolb, 2005). ELT offers both a sequential and cyclical process of the four different learning modes, including the concrete experience, reflective observation, abstract conceptualisation, and active experimentation. Concrete experience and abstract conceptualisation are modes of grasping experience, while reflective observation and active experimentation are modes of transforming experience. The first learning mode, concrete experience, is the actual experience which serves as the basis for observations and reflections in experiential learning. Reflective observation is the stage where the learner reviews and reflects on the experience, giving rise to new perspectives. These reflections are then digested into abstract conceptualisation in which the learner forms new ideas or modifications of existing concepts based on their past and new experiences. These implications lead to the last learning mode, active experimentation, where the learner actively creates new experiences (Kolb \& Kolb, 2005). ELT has been used extensively in the past to understand learning developments in a variety of different contexts, including education, management, computer science, psychology, medicine, accounting, law, and fashion (Bevan \& Kipka, 2012; Kolb, Boyatzis, \& Mainemelis, 2001; Kozar \& Connell, 2015; Laschinger, 1990; Reese, 1998; Sewchuk, 2005).

The project also integrates authentic learning in experiential learning, as the combination creates a significantly more potent learning experience (Center for Teaching \& Learning, 2015; Knobloch, 2003; Vincenti, 2010). Authentic learning involves experience with real-life problems and situations that students face outside of the classroom (Callison \& Lamb, 2004; Woolfolk, 2001). It has a constructivist approach, where the students are the centre of their own learning, and it emphasises the ability to reflect on the experience (Clark, Threeton, \& Ewing, 2010; Knobloch, 2003; Lombardi, 2007; Newmann, Marks, \& Gamoran, 1996). While the educator guides them and raises some questions, the students identify as well as solve the problems (Callison \& Lamb, 2004). Learners are also encouraged to engage in conversations in a social learning environment (Callison \& Lamb, 2004; Rule, 2006). The goal is to achieve intellectual accomplishments which are significant and meaningful as opposed to useless and trivial (i.e. repeating back facts they learned) because meaningful learning allows students to transfer learning to new situations (Newmann \& Wehlage, 1993). Likewise, this project outcome should yield a transformation from one that is extrinsically imposed (assigning the project) to one that is intrinsically driven by the student's inquiry and discovery.

\subsection{Assessment of the ELT learning}

The students reflect at the end of the project in order to record the transformational outcomes of the authentic experiential project. Metacognitive (reflective) experiential learning is the process by which individuals understand the ways they learn from experience and themselves as learners and use that understanding to improve their learning effectiveness' (Kolb \& Kolb, 2012, p. 2234). In other words, it helps the students to understand and assess what they have learned from the project. Metacognition helps to assess whether the goals have been met. In this project, the students' reflections can specifically reveal the transformation of how the authentic experiences from the project created meaningful applications in their lives. The four sequential learning modes in ELT were used to record this developmental transformation in the students' knowledge and skills relevant to careers in multichannel retailing.

The implementation of the authentic experiential learning project is first discussed, followed by the students' qualitative responses from an open-ended questionnaire at the end of the semester. 


\section{Experiential group project in multichannel retailing}

\subsection{Background}

Multichannel retailing is a class in the fashion management programme designed to build the students' knowledge and skills relevant to multichannel retailing. This class incorporated an authentic experiential project, which complemented the textbook and lectures. Poloian's (2009) Multichannel retailing was used as the textbook for the class and the lectures were adapted from the textbook. Each group of four students was assigned to develop an online presence using the information from the lectures and textbook, including mock email promotions, Facebook posts, and a non-transactional website for a brick and mortar store near the university. With the aforementioned need for multichannel skills in retailing today, the project was intended to educate students on the following in the context of having a real brick and mortar store and target market:

(1) Developing concrete skills in implementing an online presence for brick and mortar stores.

(2) Understanding the cohesiveness of the retail channels of one business entity as well as the unique function of each retail channel.

\subsection{Store review}

Each group of students was assigned to find a real brick and mortar store of their choice near the university without an online presence at the beginning of the semester. In this project, all of the student groups picked fashion (apparel and accessories) stores or beauty salons, with the exception of one restaurant and one coffee shop. Using real stores allowed the students to gain experience with real-life problems and situations outside of the classroom (Callison \& Lamb, 2004; Woolfolk, 2001). However, given the challenges of finding stores in town that were willing to work with them, students were also allowed to find stores that already had a poorly integrated online presence (based on instructor's discernment) with their brick and mortar stores. In authentic learning, it is common to face unpredictability, and is important to improvise based on the given scenario (Callison \& Lamb, 2004). Thus, the students who worked with the stores that had the poorly integrated online presence were asked to start from scratch. Although not intended, the stores that the students used were all small businesses in nature.

In order to understand the context of the store and its target market, the students had to write a report on the store's mission statement, SWOT analysis, target market, differential advantage (unique positioning of the store), and the store's future goals. Assigning students to identify the needs of the store as well as to resolve them is also an indication of using authentic learning (Callison \& Lamb, 2004). In order to obtain the information, students were assigned to ask the store owner/managers this set of information and hand in a report before moving onto the online implementation. The interaction with the store owners encouraged students to engage in conversations in a social learning environment (Callison \& Lamb, 2004; Rule, 2006).

\subsection{Online presence}

The information on the store backgrounds prepared the students to develop the mock email promotions, Facebook posts, and website for each retail store. The details of creating each of these mediums were all discussed in class. The students were also encouraged to examine and mimic how existing similar retailers set up their online presence. Creating the online presence enables the students to develop technical skills in implementing online presence for the brick and mortar store. Further, it allows students to understand the need to manage each of the three different online platforms uniquely but cohesively with the store image and with the goals of the original brick and mortar store.

\subsubsection{Email and Facebook assignment}

The students were first assigned to send out email promotions of events and sales in the store that can be targeted to their old and potential customers. In addition, the students also had to create a business Facebook account. Facebook was selected as the representative social media, as it is the most popular form of social media used by businesses today. Facebook posts were intended to promote updates on the business to excite customers into visiting the brick and mortar store. For both the Facebook posts and email promotions, students were assigned to create five different contents dispersed throughout the semester. The repetition was important for the students to learn how to change the contents based on real-life events (ie. Halloween, Homecoming, Thanksgiving, etc.), while consistently adhering to the store image and goals.

\subsubsection{Website assignment}

Finally, towards the end of the semester, the students were assigned the task of creating a Wix.com (free web development site) account, developing a non-transactional website, and integrating visual fluency into the website. The website was kept non-transactional mainly to serve as an informational platform to drive traffic into the brick and mortar store.

\subsection{Final implementation}

The final implementations were collected electronically: The email promotions as well as the Facebook site address and website (Wix.com) username and password were emailed to the instructor. In addition to handing in the final 
products, students were assigned to write a final report on how the mediums were implemented in line with the brick and mortar store image and goals. They were also assigned to share their final work with the stores they communicated with.

Finally, the students were required to present an oral presentation of the store's background and other information that helped to build the online presence. Apart from building presentation skills, oral presentations provided an opportunity for students to observe how other groups coherently created their online presence in line with the brick and mortar stores. The student works were assessed by the educator at the end of the semester. Assessing the work showed that the students incorporated the online presence based on the store image and goals of the brick and mortar stores.

\section{Method}

\subsection{Research questionnaire}

After the students were finished with the project at the end of the semester, the instructor (researcher) invited them to reflect on their project experience and anonymously respond to a series of open-ended questions online as an extra credit assignment. They were given an alternative assignment if they chose not to participate in the questionnaire. Extra credit was used to give students the option of responding. This was done in an attempt to mitigate potential bias to give positive feedback and to receive a more organic and honest reflection of what they learned through the project. Since authentic experiential learning involves student-centred learning, and emphasises the ability to reflect on the experience (Clark et al., 2010; Knobloch, 2003; Lombardi, 2007; Newmann et al., 1996), the learning assessment needs to derive from the students' standpoint. Thus, although other forms of assessment were collected in regard to the project (the final online implementations, report, oral presentation, reflections), only the reflections were used to assess the student learning outcomes. The student reflections were intended to foster understanding of how the project helped them to transform the sequential learning modes to a point where they have applied meaningful skills outside of the classroom environment.

With institutional review board approval, the students were specifically asked to describe: (1) their overall experiences of the project (concrete experiences), (2) how they applied the textbook to the project (reflective observation), (3) what they learned or realised from the project and from working with the stores (abstract conceptualisation), and (4) the benefit of this project outside of the course (active experimentation). Each of the four questions represents each of the four modes of experiential learning. Thus, these questions helped guide students to reflect on each of the four modes of experiential learning as well as helped the researcher assess learning outcomes at each of the stages.

\subsection{Data collection and analysis}

The instructor (researcher) collected and organised the responses. The data collection was used to explore how the experiential project built knowledge and skills to prepare the students for careers in the world of multichannel retailing. The responses from each of the four learning modes of experiential learning (concrete experience, reflective observation, abstract conceptualisation, and active experimentation) were used as a guide to examine and record the transformation of learning.

The process and rationale for assessing each of the four modes of experiential learning to ensure the themes were correctly allocated is as follows:

The first stage reflected on the concrete experience of the experiential project. Concrete experience refers to the actual experience that the students encountered with the project, and reflective observation reviews and reflects on that actual experience. Because it is also important to observe how students transformed their learning, the next stage of this study examined the students' connections between their classroom knowledge and the actual experience through the project, which together provide that information. Thus, the students were asked to reflect on their overall experiences with the project and to describe how they applied the textbook to it. The third stage, abstract conceptualisation, refers to how the students have formed new ideas based on their observation. Accordingly, the students were asked to describe what they learned or realised from the project experience. In this stage, the instructor particularly examined how the students formed novel conclusions which were not taught to them, but rather formed on their own from being the centre of their own learning. This stage reflects how the students have identified real issues (even ones outside of project requirements) and managed to solve them on their own. The last stage is active experimentation, which entails the learner creating new experiences for themselves outside of this experiential project. For this, the students were asked to describe the benefit of the project outside of the course.

Multiple cycles of interpretations were conducted on the students' responses (Creswell, 2007; Neuman, 2011). First, the responses were read in its entirety to obtain a holistic view of the text. Then, the student responses were grouped into emerging themes, based on the rationale for assessing each of the four modes of experiential learning. This procedure was repeated, allowing reflection on the previously interpreted text in light of newly developed understandings.

The theme allocation and interpretations were also reviewed by an independent researcher whose expertise is in pedagogy and qualitative methods to ensure that interpretations were consistent with the pedagogy literature and study data. Second rounds of interpretations occurred to gain a consensus between the two researchers. For example, one researcher interpreted the quotation 
It makes me feel excited to be a part of the project knowing they [stores] support us. The owner of [xxx] was very accepting of our changes and she seemed happy that she was able to create her website especially since she was not as knowledgeable as we are on e-commerce

to belong in the reflective observation under 'Exposed to the challenges associated with multichannel retailing', but after a deep discussion between both researchers, they agreed that the quotations belonged under abstract conceptualisation in 'Filling the gap by developing the online presence for the brick and mortar businesses'. Sixteen percent ( 4 out of 25) of themes were reread and modified.

In the next section, emerging themes were allocated within each stage of the experiential learning based on the students' responses.

\section{Student learning outcomes}

\subsection{Respondents}

Sixty-seven out of the 77 students in the class responded. The qualitative data were then downloaded for analyses. The students were composed of juniors (at their third year at the university) (6) and seniors (fourth/last year at the university) (61), with an average age of 23 years. All except one student were females. The majority (85\%) of the students were White/European-American followed by $13 \%$ black/African-American and $2 \%$ other ethnicities. Multichannel retailing was an elective (optional) class in the fashion management programme so they likely took this class for their own interest. Thus, these students in general shared more similarities than differences in their educational background and interests.

\subsection{Concrete experience}

In this stage, the students were asked to reflect on their actual experiences. Through this project, the students expressed how they were able to understand the 'ins and outs' of the actual retail businesses they worked with. The students used this store information with what they have learned from their classroom textbook and lecture together to implement the online presence.

\subsubsection{Learning the 'ins and outs' of an actual retail business}

The majority of the students expressed that they were able to develop a personal relationship with the store owners and employees by asking them questions about the background of the stores. Through this relationship, the students gained knowledge of the business operations, the products or services sold, and the store's future goals. These were all experiences which could not have been learned through textbooks:

The project allowed us to create a more personal relationship with the employees and/or store owners.
It also allows us to learn what goes into owning and operating a business. (Student A)

I got to experience talking with the workers and owner of the store and learned a lot about them from what they carry and how the store is run. The owner thought it was awesome of us to come in and help him out with his Facebook page and website. (Student B)

I was able to challenge myself through the whole process. I have never had to represent a real retail store before. In all my other [xxx] classes, we have always made up fake companies. Representing a real $[\mathrm{xxx}]$ retailer was very different and interesting. I loved getting involved with an actual business, and learning all the ins and outs of the company. The project helped me get a look at how real life retailers function. (Student C)

\subsection{Reflective observation}

In the second stage of the experiential learning, the students were asked to reflect on their experiences and describe how they applied the textbook to the project. The students realised that by learning about the store backgrounds, they were able to understand how the implementation of the store's online presence was dependent upon the store's agenda. In addition, an overwhelming number of students observed that there were gaps in the online presence of the actual businesses in contrast to the types of examples they were used to observing in their textbook.

\subsubsection{Bringing classroom knowledge to life}

Besides the store background, the students used the materials they learned in class to implement the online presence. For example, some students mentioned incorporating the 'elements and principles of design' learned in class to create the website. Others mentioned learning about implementing the cohesive use of the online presence with the brick and mortar to fully represent the store.

In our final presentation we showed our Facebook and website that we had made for our company. During class we learned different tips on how to execute a website and Facebook the right way. We used this info and were able to make really cool pages. We also learned a lot about SWOT analysis which we incorporated into our project. It helped us map out the strengths, weaknesses, opportunities, and threats of the company. (Student D)

In class we talked about what makes a good webpage, which we used to the best of our ability when creating our webpage for our local store. We also talked about how different channels are used but how they all need to incorporate each other. When creating our webpage, email, and Facebook we made sure it has the same feel and vibe as the brick and mortar store. (Student E)

The elements and principles of design [learned in class] helped us effectively design our webpage and e-mails. We made sure we had a cohesive colour scheme and good balance and proportion when we made our website. This helped our Facebook page, e-mails and website all go together cohesively to represent our store. (Student F) 


\subsubsection{Online implementation depends on the store's agenda}

Learning what the stores carry and how the stores are run guided the students to determine what the stores needed from them. It challenged them to come up with creative ideas to enhance the store's online presence. Although they were taught this before in class, implementing the project themselves and having to put the pieces together enabled them to fully understand and build knowledge about the connectedness of the retail channels.

\begin{abstract}
Making the SWOT analysis helped us effectively establish what the store lacked and needed to improve. By setting goals and strategies we were able to design our webpage, emails and Facebook page to communicate and display to consumers what the store offered. (Student G)

I was able to challenge myself creatively, and effectively work with a group. It was also very cool to talk to store owners about how they want to portray themselves as a company, and being able to create a website and Facebook page that really brought that portrayal to life. (Student $\mathrm{H}$ )

I learned a lot through having to complete different yet cohesive tasks involving developing and maintaining a new multichannel world for [Store X]. (Student I)
\end{abstract}

\subsubsection{Exposure to the challenges associated with multichannel retailing}

As aforementioned, the students worked with a range of stores from those without any online presence to those with poorly integrated online presence. Consequently, the students were able to point out the gaps in (or a lack of) online presence that the actual stores were facing, in contrast to the ideal multichannel retailing practices which was observed through the textbook examples. The students identified a variety of different gaps, depending on the type of store they worked with.

\footnotetext{
The store has no online presence at all. Shoppers looking for them online currently will find nothing and this could cause them to miss out on sales. (Student J)

It was kind of shocking how so many retailers did not have a website, or did not have an up-to-date one. (Student K)

Their Facebook was lacking. Only told store hours, location, etc. There was no updates on work, new artists, etc. (Student L)
}

These challenges may have been due to the nature of the stores being small and local, but it still exposed the students to the realistic types of challenges businesses face today in multichannel retailing.

\subsection{Experience through abstract conceptualisation}

In this learning stage, the students formed new conclusions that they could not have learned through the class textbook or lecture alone. For example, by implementing the online presence, the students started to discern which platform (between the email, Facebook, and website) was most essential for each store context. Furthermore, the students were able to not only identify, but also resolve some of the gaps that they were noticing about the stores.

\subsubsection{Realising the benefit of one online presence over another}

Students started discerning that one form of online presence was more beneficial than another, depending on each store. For example, some groups mentioned that the website was the most important online presence to build, and that the stores should create a transactional site going forward. In contrast, there were students who thought Facebook was the most important online presence, and thought that the website should be kept non-transactional.

I think, by far, [Store Y] would benefit from having the website the most. I feel like a website can give customers a better feel for what the companies characteristics are, while not only providing information. (Student $\mathrm{M}$ )

The store currently does have a Facebook. However, it isn't interactive and rarely updated. I think a fresh Facebook page that really reached out to the target market would help drive sales. Also, it would serve to build the personal touch that the store values so much. (Student N)

For this particular store [a coffee shop] having a website serves only the purpose of informing about products being offered, which could easily be done on more useful outlets like social media. (Student O)

\subsubsection{Filling the gap by developing the online presence for the brick and mortar businesses}

Because the businesses in the textbook examples were already multichannel, the students neither thought about the value of actually having the online presence nor the negative consequences of not having an online presence. From identifying and resolving the gaps by creating an online presence for the stores, the students were able to comprehend the benefits of actually having an online presence for each business. Some students even received positive feedbacks from their stores on the future use of the implementations.

I think by doing this project we gave the retailer some new ideas that could help their company. Business X had very poor marketing, and I think we helped them realize how important that really is. (Student P)

I loved hearing other groups mention in their presentations that some of the store owners were interested in keeping their websites or Facebook pages active in order to expand them. It made me realize that this project also might have benefited a lot of the store owners by opening their eyes to a new perspective and making them think about how they can improve their businesses. (Student Q)

It makes me feel excited to be a part of the project knowing they [stores] support us. The owner of [xxx] was very accepting of our changes and she seemed happy that she was able to create her website especially since she was not as knowledgeable as we are on e-commerce. (Student R) 


\subsection{Experience through active experimentation}

In the last stage, a majority of the students expressed how the project cultivated their skills outside of the course, especially for future careers in multichannel retailing. Additionally, students expressed confidence in building an online presence for their future businesses or careers. Others had already started implementing the online presence for their families' businesses during the semester.

\subsubsection{Use of knowledge and skills in the future}

Without prior experience in creating an online presence (asked in class), an overwhelming number of students expressed that they used the project to build the necessary knowledge and skills. Because the students were aware of the changing dynamics of the retail industry, they wanted to add this project to their resumes and student portfolios. They also expressed the usefulness of the experiential project for their future goals.

I enjoyed learning all about the way business operates as well as making my own website. Not only was this a great experience but I can definitely use this in my future career. (Student S)

I learned a lot with the project, with being able to work with a company in town and learn to create emails, Facebook updates, and a website for the company. I thought that it was very useful information that I will be able to use later on and possibly add it to my resume. (Student T)

I really found it [the project] beneficial for my current career interests and goals because I am interested in potentially starting my own e-retailer and expanding into brick and mortar, or vice versa. (Student $U$ )

I had never made a webpage or website before, so I feel this project will help me in the future if I ever want to make one. (Student V)

\subsubsection{Planning or already helping to expand their family business}

Some students proactively took this project one step further by applying what they learned from their projects to help their family members expand their businesses online. While certain students only had plans, others were already helping their families to expand their businesses during the semester.

I think my experience with this project can help my Dad with his remodelling business. Currently, he only has a Facebook site and I think it would be very beneficial for him to have a website as well. (Student W)

It has already helped expand my father's business in order to reach more customers. (Student X)

I have created a website for my uncle's business that I know was very helpful. I think I want to help indulge him in social media. (Student Y)

\section{Discussion, future research, and limitations}

\subsection{Discussion}

Although class textbooks and lectures are used to prepare students for careers in multichannel retailing, there is a lack of educational literature on the experiential learning practices. This paper demonstrates how an authentic experiential learning project can provide students with a real experience that can help them create transformational and meaningful learning experiences relevant to careers in the multichannel retailing world. As multichannel retailing is continually redefined and changed in the industry, this project is valuable in helping students in the fashion business major to get a hands-on experience with multichannel retailing and to meet the needs of the industry. This experiential project can be used in any retailing class involving the discussion of multichannel retailing to develop similar learning outcomes. It can be replicated and implemented to create a conceptual and tangible understanding of the multichannel retailing world today, and to build concrete skills relevant to careers in multichannel retailing.

The emerging themes at each learning stage helped guide the transformation of the students' learning into meaningful knowledge. First, in the concrete experience stage, many of the students mentioned how having that interaction of the actual store owners really helped them to understand the function and current goals of the store. In authentic learning, those social interactions are an important manner in which students can achieve this (Callison \& Lamb, 2004; Rule, 2006).

In the reflective observation stage, the students described how they combined the context of the actual stores with the theoretical concepts learned in the classroom through the textbook and lectures to guide them in creating the online presence for the project. They realised that both the theoretical concepts and the real store context were needed to implement the online presence. They further realised the discrepancy in the idealised world of multichannel retailing learned in textbooks versus what they actually saw through this project. Thus, connecting the theory and practice helped students to compare and contrast the textbook and their actual experience.

In the abstract conceptualisation, the students started to show signs of learning on their own. They were making sense of the multichannel retailing world through what they were experiencing. For example, students were discerning which online platform worked best for the stores they were working with. Other students realised that many of the stores were not knowledgeable about the online store platform and that they had a special opportunity to overcome that challenge.

Finally, in the active experimentation stage, the students felt that the experiential project had tangible benefits towards their careers. Some students felt that this experience built their resume, while others wanted to open up their own online business with the experience they 
gained. Some students have already acted upon their experiences and have started to create online platforms for their families' brick and mortar stores.

One of the key learning goals of the project throughout all of the stages of the learning experience was for the students to conceptually understand the cohesiveness of the different retail channels for one business entity and apply the concept through implementing the online presence. In the project, the students were assigned the task of creating the online presence cohesively by adhering to each store's background and goals, which were modelled by the textbook examples. By implementing the different online platforms based on the different brick and mortar store backgrounds and goals, the students were able to learn on both a theoretical and practical level how each retail channel needed to be cohesive. Through the project, the students realised that creating a cohesive online presence is challenging but beneficial for the survival of retail businesses today. Understanding the cohesiveness of the different retail channels is an important knowledge set for students in finding any job in retailing today.

Another key learning goal was for students to understand the different functions of each online presence. According to their responses, students learned to use each medium differently for the stores they were working with. In the abstract conceptualisation stage, the students were able to discern which platforms may be most beneficial for the stores they worked with. This demonstrates how the students were able apply new ideas that were not taught or directed by the instructor, but rather learned on their own through identifying and resolving the problems themselves. There is no one recipe for which platform all customers will like today, so being able to discern and distinguish which channels are advantageous for specific stores in the future is a valuable asset to any company (Jang, Chang, \& Chen, 2013; Kietzmann, Hermkens, McCarthy, \& Silvestre, 2011).

Another key learning goal was to create a project where students could build online skills. Through the project, the students came up with their own strategies for how they were going to implement the online presence. They then coherently created the email promotions, Facebook posts, and website. These online skills are essential and growing in demand for all students' future careers, regardless of their major (Choi \& Rasmussen, 2009; Fahmy, 2008). Hence, fostering online skills is needed and highly encouraged within higher education in order to prepare students for today's job demands (Kim \& Bonk, 2006; Robinson \& Hullinger, 2008).

\subsection{Future research}

Although student feedback about the project demonstrated the transformation of their learning through the project, another form of assessment which would have strengthened the support is the store owners' feedback on the students' learning and performance. Future research can therefore also collect some feedback from the store owners on how satisfied they were with the students' work, as well as their likelihood of hiring the students if they needed an online account manager.

Additionally, the effectiveness of the project in the students' careers cannot be clearly demonstrated unless there is a follow-up study after students have worked for a while in the multichannel retailing environment. This type of follow-up study is also a possible future research.

Furthermore, instead of restricting the students to specifically create mock email promotions, Facebook posts, and website, a future study can allow the students to make their own discernment on which platforms to create. This change could create a more authentic multichannel interaction, depending on the context of each business scenario.

Finally, because of the difficulty in finding businesses that were willing to work with the students, another alternative would be to assign students mock scenarios instead. Furthermore, depending on the size of the class, the students can be allowed to either work alone or in groups.

\subsection{Limitations}

One major limitation of the study is the social desirability bias. Although the responses were analysed anonymously to encourage honest responses, the students could have still felt some pressure to write positive feedback because of the extra credit incentive given to respond to the questionnaire. Caution is recommended for generalising study findings to other contexts. In addition, there was a lack of empirical measurement tools for the success of the online presence. Although the students' responses were reflective of the outcomes of their learning, there was not an actual budget or sales report to measure the effectiveness of the online presence. As mentioned, a follow-up study after students have worked for a while in a multichannel retailing environment would help develop a compelling conclusion.

Furthermore, the students were assigned to show the final project to the store owner or manager they communicated with. However, the store's feedback was not required for the project. It would have been beneficial to use that feedback to evaluate the students' learning outcomes. In addition, given the nature of the fashion business major, all students except one were female. This could have also influenced the student outcomes.

\section{Disclosure statement}

No potential conflict of interest was reported by the author.

\section{References}

Agnihotri, A. (2015). Can brick-and-mortar retailers successfully become multichannel retailers? Journal of Marketing Channels, 22(1), 62-73. 
Bevan, D., \& Kipka, C. (2012). Experiential learning and management education. Journal of Management Development, 31(3), 193-197.

Callison, D., \& Lamb, A. (2004). Key words in instruction: Authentic learning. School Library Monthly, 21(4), 34-39.

Carlson, J., \& O'Cass, A. (2011). Managing web site performance taking account of the contingency role of branding in multichannel retailing. Journal of Consumer Marketing, 28(7), 524-531.

Center for Teaching and Learning. (2015). Experiential learning defined. Retrieved from http://ctl.utexas.edu/teaching/engag ement/experiential-learning/defined

Choi, Y., \& Rasmussen, E. (2009). What qualifications and skills are important for digital librarians positions in academic libraries? A job advertisement analysis. The Journal of Academic Librarianship, 35(5), 457-467.

Clark, R. W., Threeton, M. D., \& Ewing, J. C. (2010). The potential of experiential learning models and practices in career and technical education \& career and technical teacher education. Journal of Career and Technical Education, 25(2). Retrieved from http://scholar.lib.vt.edu/ejournals/JCTE/ v25n2/clark.html

Creswell, J. W. (2007). Qualitative inquiry and research design: Choosing among five approaches (2nd ed.). Thousand Oaks, CA: Sage.

Diamond, J., Diamond, E., \& Litt, S. (2015). Fashion retailing: A multi-channel approach (3rd ed.). New York, NY: Bloomsbury.

Fahmy, S. (2008). How online journalists rank importance of news skills. Newspaper Research Journal, 29(2), 23-38.

Heywood, L. (2013, May 17). Analysis: Recruiting and retaining multichannel experts. Retail Week. Retrieved from http:// m.retail-week.com/5049099.article

Hsiao, C. C., Yen, H., \& Li, E. Y. (2012). Exploring consumer value of multi-channel shopping: A perspective of meansend theory. Internet Research, 22(3), 318-339.

Hsieh, Y. C., Roan, J., Pant, A., Hsieh, J. K., Chen, W. Y., Lee, M., \& Chiu, H. C. (2012). All for one but does one strategy work for all? Building consumer loyalty in multi-channel distribution. Managing Service Quality: An International Journal, 22(3), 310-335.

Jang, Y. T., Chang, S. E., \& Chen, P. A. (2013). Exploring social networking sites for facilitating multi-channel retailing. Multimedia Tools and Applications, 74(1), 159-178.

Kietzmann, J. H., Hermkens, K., McCarthy, I. P., \& Silvestre, B. S. (2011). Social media? Get serious! Understanding the functional building blocks of social media. Business Horizons, 54(3), 241-251.

Kim, K., \& Bonk, C. J. (2006). The future of online teaching and learning in higher education: The survey says. Educause Quarterly, 29(4), 22-30.

Knobloch, N. A. (2003). Is experiential learning authentic? Journal of Agricultural Education, 44(4), 22-34.

Kolb, A. Y., \& Kolb, D. A. (2005). Learning styles and learning spaces: Enhancing experiential learning in higher education. Academy of Management Learning \& Education, 4(2), 193-212.

Kolb, A. Y., \& Kolb, D. A. (2012). Experiential learning theory. In N. M. Seel (Ed.), Metacognitive experiential learning (pp. 2234-2236). New York, NY: Springer.

Kolb, D. A. (1984). Experiential learning: Experience as the source of learning and development. Englewood Cliffs, NJ: Prentice-Hall.

Kolb, D. A., Boyatzis, R. E., \& Mainemelis, C. (2001). Experiential learning theory: Previous research and new directions. Perspectives on Thinking, Learning, and Cognitive Styles, 1, 227-247.
Kolb, D. A., Rubin, I. M., \& McIntyre, J. (1971). Organizational psychology: An experiential approach. Englewood Cliffs, NJ: Prentice Hall.

Kozar, J. M., \& Hiller Connell, K. Y. (2015). The fashion internship experience: Identifying learning outcomes in preparing students for the 'real world'. International Journal of Fashion Design, Technology and Education, 8(1), 3-11.

Laschinger, H. K. (1990). Review of experiential learning theory research in the nursing profession. Journal of Advanced Nursing, 15, 985-993.

Lewis, J., Whysall, P., \& Foster, C. (2014). Drivers and technology-related obstacles in moving to multichannel retailing. International Journal of Electronic Commerce, 18(4), 43-68.

Lombardi, M. M. (2007). Authentic learning for the 21st century: An overview. Educause Learning Initiative, 1(2007), 1-12.

Monster.com. (2014). Jobs. Retrieved from http://www.monster. $\mathrm{com} / ? \mathrm{disRe}=$ true

Morgan Stanley. (2013, January 6). Ecommerce disruption: A global theme - transforming traditional retail. Retrieved from http://www.rundlemall.com/bm.doc/ecommerce_bp 0106131.pdf

Neslin, S. A., Grewal, D., Leghorn, R., Shankar, V., Teerling, M. L., Thomas, J. S., \& Verhoef, P. C. (2006). Challenges and opportunities in multichannel customer management. Journal of Service Research, 9(2), 95-112.

Neuman, W. L. (2011). Social research methods: Qualitative and quantitative approaches (7th ed.). Whitewater, WI: Pearson.

Newmann, F. M., Marks, H. M., \& Gamoran, A. (1996). Authentic pedagogy and student performance. American Journal of Education, 104(4), 280-312.

Newmann, F. M., \& Wehlage, G. G. (1993). Five standards of authentic instruction. Educational Leadership, 50(7), 8-12.

Nikolaeva, R. (2006). E-commerce adoption in the retail sector: Empirical insights. International Journal of Retail \& Distribution Management, 34(4), 369-387.

Poloian, L. G. (2009). Multichannel retailing. New York, NY: Fairchild.

PWC. (2011). Understanding how US online shoppers are reshaping the retail experience, Retrieved from http://www. pwc.com/en_US/us/retail-consumer/publications/assets/pwc -us-multichannel-shopping-survey.pdf

Reese, J. H. (1998). Enhancing law student performance: Learning styles interventions. Saratoga Springs, NY: The National Center on Adult Learning.

Robinson, C. C., \& Hullinger, H. (2008). New benchmarks in higher education: Student engagement in online learning. Journal of Education for Business, 84(2), 101-109.

Rule, A. C. (2006). Editorial: The components of authentic learning. Journal of Authentic Learning, 3(1), 1-10.

Sewchuk, D. H. (2005). Experiential learning - a theoretical framework for perioperative education. AORN Journal, 81(6), 1311-1318

Teltzrow, M., Meyer, B., \& Lenz, H. (2007). Multi-channel consumer perceptions. Journal of Electronic Commerce Research, 8, 18-31.

Verhoef, P. C., Kannan, P. K., \& Inman, J. J. (2015). From multichannel retailing to omni-channel retailing: Introduction to the special issue on multi-channel retailing. Journal of Retailing, 91(2), 174-181.

Vincenti, G. (Ed.). (2010). Teaching through multi-user virtual environments: Applying dynamic elements to the modern classroom: Applying dynamic elements to the modern classroom. Hershey, PA: IGI Global.

Woolfolk, A. (2001). Educational psychology (8th ed.). Boston, MA: Allyn \& Bacon. 